\title{
Inferential sets, order effects, and the judgment of persons*
}

\author{
ADRIAN K. LUND, STEVEN A. LEWIS \\ and VICTOR A. HARRIS \\ State Liniversity of New York at Buffalo. Buffalo, N.Y. 14226
}

Jones \& Thibaut (1958) posited three distinctive inferential sets: value maintenance, situation matching, and causal genetic. One hundred and forty-four male undergraduates, exposed to a stimulus person varying on the dimensions of personality strength (strong vs weak) and norm clarity (specified vs unspecified), made sequential judgments from one of three different orderings of these inferential sets. Results reveal that different set orderings led to different judgments; additionally, Ss judged the strong SP as more responsible, more likable, and more appropriate in behavior than the weak SP. These results are discussed in light of a model which argues that whenever one person evaluates the activities of another his evaluation is at least partially based on how he feels he would have behaved under similar circumstances.

Recently, social psychology has witnessed a tremendous growth of theory and research concerned with the general issue of how people make judgments about others. This development, stemming from Heider's writings (1944) and given its current impetus by more empirically based formulations (Jones \& Davis, 1965; Kelley, 1967), has been labeled attribution research. In an early paper in this area, Jones \& Thibaut (1958) argued that a person's expectations about a given interaction affect that person's openness to different types of information (selectivity hypothesis) and the manner in which the person integrates the information (transformation hypothesis). These different selective and transformational properties are subsumed under the rubric of inferential set. Simply stated, one person's view of another (attribution) will be determined by his inferential set at the particualr time. Jones and Thibaut elucidate three distinct inferential sets: value maintenance (VM), situation matching (SM), and causal-genetic (CG), which correspond to, or perhaps are derived from, the three end states of goal attainment, application of social sanctions, and analysis of other's personality dimensions, respectively.

Although the above inferential sets, or, for that matter, end states, do not appear in isolation in normal interactions, it is of heuristic value to investigate their effects in "pure form." In such an attempt, Jones \& deCharms (1958) used variations in instructions to induce perceivers (Ss) to adopt different inferential sets in "perceiving and judging" a standard stimulus person's behavior. In all cases, Ss listened to a tape recording of an interview between an ex-prisoner of war (SP) who had signed several Communist propaganda statements

*This paper is sponsored by Edward S. Katkin, who takes full editorial responsibility for it. and a psychologist. Although aware of the fact that "... the use of instructions for set arousal seem superficial and somewhat naive... [Jones \& Thibaut, 1958, p. 173]," they argued that the method does avoid the problems of attempting to hold actual interactional behavior constant and does in fact yield useful information. Jones and deCharms essentially found support for their notions in that the set-arousing instructions caused Ss to attend differentially to the specific informational content of the tape (selectivity) and also affected the way in which judgments were made (transformation).

Taking the findings of Jones and deCharms along with the large literature on order effects in impression formation (cf. Hastorf, Schneider, \& Polefka, 1970), it appears reasonable to examine the effects of differential orderings of set arousal on Ss' judgments. As Jones and Thibaut point out, both value maintenance and situation matching sets call forth evaluative inferences, while the causal-genetic set does not. It is a reasonable assumption that evaluative judgments tend to possess greater significance for the "judge's" future activities than do the nonevaluative ones, and, thus, we predict that different orderings of the value maintenance and situation matching sets will have more impact than orderings which merely change the position of the causal-genetic set (Hypothesis 1).

The present study was modeled after the Jones \& deCharms (1958) report. However, the basic design was extended to investigate the effects of set ordering and also to investigate, in more complete fashion, the potential interactive effects of the stimulus person's personality and the clarity or lack of clarity of norms governing the behavior in the particular (prisoner of war) situation. Jones and deCharms examined only two of the four logical combinations of personality and norm clarity -a strong (mentally healthy) person operating under conditions where the norms were unspecified and a weak (mentally unhealthy) person operating under conditions where the norms were clearly specified. In both cases, the SP performed behavior which was counternormative. Since later studies have focused upon the effects of norm clarity, or role expectation, on S's judgments (Jones, Davis, \& Gergen, 1961: Jones \& Harris, 1967), it is reasonable to examine all four possible combinations of norm clarity and personality strength. The information about norms was expected to affect people most in the SM set where Ss should decide that the sergeant in the specified condition has violated clear societal mores. Thus we predict that Ss will rate the sergeant in the specified condition as deserving more punishment than the sergeant in the unspecified condition (Hypothesis 2). 


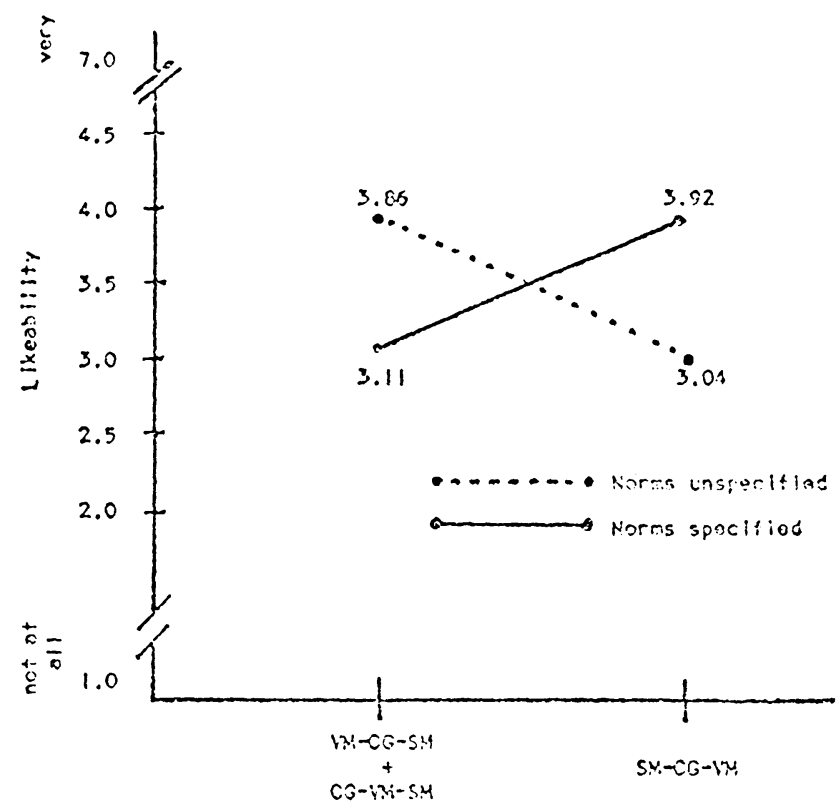

Fig. 1. Interaction of norm clarity and set order on perceived likeability.

In addition, the present investigation was concerned with how Ss' judgments of another affect their perceptions of their own (potential) behavior. The research and writing on bystander intervention clearly indicates that most people feel that a person who does not help is not a good person and that they themselves would help (Latané \& Darley, 1970). In the present context, the question arises as to Ss' perceptions (either positive or negative) of the SP and their descriptions of what they would do in the POW situation. Deriving our prediction from the bystander literature, we expect that the more positively the Ss evaluate an ex-POW, the more likely they will be to assert that they also would sign enemy' propaganda statements (Hypothesis 3).

The above considerations led to the present design, in which Ss were induced to make sequential judgments of an SP utilizing a different inferential set with each judgment. Since any attempt to examine all possible orderings of the three sets would have been prohibitively expensive in terms of the number of Ss required, a selection of three orderings was used. Thus, Ss made judgments in the order of VM, CG, SM; or CG, VM, SM; or SM, CG, VM. These three orders allow for the examination of the effects of each inferential set uncontaminated by subsequent inductions (thus providing a conceptual replication of the Jones and deCharms study), as well as allowing an examination of the effects of reversing the sequence of value maintenance and situation matching sets.

\section{METHOD}

Subjects

One hundred and forty-four male undergraduate students at the State University of New York at Buffalo took part in the experiment as part of their requirement for introductory psychology.
Procedure

The Ss reported in groups to a large classroom, where they heard one of four tape-recorded interviews, corresponding to the four SPs generated by the dimensions of personality (strong vs weak) and norm! clarity (specified vs unspecified) discussed earlier. After the tape, Ss made judgments of the SP on the basis of the three inferential sets. The set inductions were accomplished by having Ss role-play a fellow soldier (value maintenance set), a medical-physiological board member (casual genetic set), and a member of a board of inquiry (situation matching set). Each set was followed by one or more 7-point rating scales pertinent to that set.

\section{RESULTS}

Ss exposed to the strong sergeant judge him as more responsible for his behavior $(p<.001)$, see him as more likable $(\mathrm{p}<.05)$, and judge his behavior as more appropriate $(p<.0004)$ than Ss exposed to the weak sergeant. In addition, there is a tendency for the sergeant in the strong condition to be seen as deserving less punishment than the sergeant in the weak condition $(p<.1017)$. In support of the order hypothesis, a significant interaction was found between the norm clarity and set order factors for SP's likability $(p<.01)$, along with a parallel tendency on the punishment variable $(\mathrm{p}<.12)$.

The specific statistical comparisons to test Hypotheses 1 and 2 indicate that Ss who experienced the VM set before the SM set (the VM-CG-SM and CG-VM-SM orders, combined) found the sergeant in the unspecified condition more likable and saw him as deserving less punishment than the sergeant in the norms-specified condition. Ss who experienced the SM set before the VM set (SM-CG-VM) show the reverse effect: the sergeant in the norms-specified condition was liked more and seen as less deserving of punishment than the sergeant in the unspecified condition (liking, interaction $p<.003$; punishment with appropriateness covaried out, interaction $\mathrm{p}<.05)$. Figures 1 and 2 show the interaction pattern for these two comparisons.

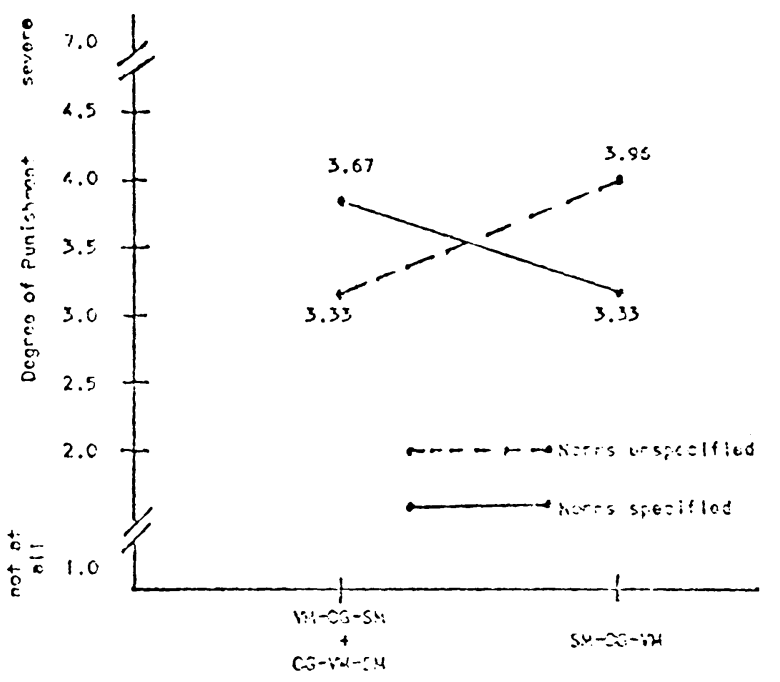

Fig. 2. Interaction of norm clarity and set order on degree of punishment deserved. 
Finally. Ss' responses to an open-ended question. "What would you have done in the sergeant's situation?" were coded (blind) into one of four categories: (1) no codable answer or "I don't know," (2) would have signed, (3) would have put up more resistance, but would probably have signed eventually, (4) would not have signed. The results of a chi-square analysis demonstrate that Ss whose SP had described himself as weak indicate that they would have held out longer than he did $\left(\chi^{2}=19, p<.001\right)$. That this chi-square value is due to the personality rather than the norm-clarity dimension is evidenced by the fact that collapsing across norm clarity leaves the chi-square value virtually unchanged $\left(\chi^{2}=17.6, p<.001\right)$, while collapsing across personality yields a nonsignificant chi-square value $\left(\chi^{2}=\right.$ $.40)$.

\section{DISCUSSION}

As did Jones \& deCharms (1958), the present study found that a weak SP was seen as deserving greater punishment than a strong SP. The meaning of their results were clouded, however, by the confounding of personality and norm clarity. By varying both norm clarity and personality, the present study avoided this confounding. The fact that a personality effect appears, but neither a norm nor a Norm by Personality interaction appears, suggests that the personality of the sergeant is the crucial factor explaining the results in both studies.

The variable of most interest to the present investigation was the order in which the Ss experienced the judgmental sets. There was a highly significant interaction between the order variable and the norm-clarity variable on the perceived likability of the SP $(p<.01)$ and a strong tendency toward an interaction between the same variables on the degree to which Ss felt the SP should be punished $(p<.07)$.

As predicted, altering the order of the evaluative sets was quite effective in producing changes in two important judgments about an SP, how likable he is and how much he should be punished for his behavior. In addition, Ss who indicated more liking of the SP also indicated that they felt he deserved less punishment. However, the actual data were inconsistent with our second hypothesis regarding norm clarity. This inconsistency becomes understandable if we take seriously the suggestion of Jones \& deCharms (1958) that Ss may not believe that the sergeant (SP) could be ignorant of the norms regarding collaboration with the enemy. One might expect such doubts to be strongest in the SM set, expecially when that set comes first (as in SM-CG-VM). If this is so, then perhaps $S s$ in the SM-CG-VM order decided that the sergeant who described the norms as ambiguous was being defensive and cowardly, while the sergeant who admitted the norms to have been well stated was seen as honest and making a clean breast of things. Thus, the finding that Ss in the SM-CG-VM order felt the sergeant deserved more punishment for his behavior in the unspecified condition than in the specified condition may represent the Ss' reaction to a different norm violation: the norm requiring that one behave like a man and "take one's medicine bravely." The weakening or reversal of this tendency in the other set orders may then be due to the fact that in those orders, Ss made other judgments of SP before taking on the SM set, and, hence, were more prone to take the sergeant's description of the situation at face value.

The most striking finding in the study is the effect of the personality variable on Ss' evaluations of SP. The stronger the judged personality of SP, the better liked he was, the more Ss felt that he was responsible for his own behavior, the more appropriate his behavior was judged to have been, the less his behavior was seen to be deserving of punishment, and the more likely Ss were to indicate that they would have behaved as had the sergeant. This finding supports Hypothesis 3 and indicates that when one person is observing another, the most salient and potent information about that other concerns his strength of character. Why this is so becomes clearer if we consider the last question asked of the Ss: "What would you have done in the sergeant's situation?" There is an interesting relationship between the Ss' assessments of what they would have done and how they felt about what the sergeant did. Specifically, Ss who were exposed to the strong sergeant indicated a greater tendency to do as the sergeant had done and were more favorable in their ratings of the sergeant than Ss exposed to the weak sergeant. This relationship implies that whenever one person evaluates the activities of another, his evaluation is at least partially based on how he himself feels he would have behaved given the same set of circumstances.

\section{REFERENCES}

Hastorf, A. H., Schneider, D. J., \& Polefka, J. Person perception. Reading, Mass: Addison-Wesley, 1970.

Heider, F Social perception and phenomenal causality. Psychological Review, 1944, 51, 358-374.

Jones, E. E., \& Davis, K. E. From acts to disposition: The attribution process in person perception. In L. Berkowitz (Ed.), Advances in experimental social psychology. Vol. 2. New York: Academic, 1965. Pp. 220-266.

Jones, E. E., Davis, K. E., \& Gergen, K. J. Role playing variations and their informational value for person perception. Journal of Abnormal \& Social Psychology, 1961, 63, 302-310.

Jones, E. E., \& deCharms, R. The organizing function of interaction roles in person perception. Journal of Abnormal \& Social Psychology, 1958, 57, 155-164.

Jones, E. E., \& Harris, V. A. The attribution of attitudes. Journal of Experimental Social Psychology, 1967, 3, 1-24.

Jones, E. E., \& Thibaut, J. W. Interaction goals as bases of inference in interpersonal perception. In $R$. Tagiuri and $L$. Petrullo (Eds.), Person perception and interpersonal behavior. Stanford: Stanford University Press, 1958. Pp. 151-178.

Kelley, H. H. Attribution theory in social psychology. In D. Levine (Ed.), Current theory and research on motivations. Lincoln: University of Nebraska Press, 1967. Pp. 192-238.

Latané, B., \& Darley, J. The unresponsive bystander: Why doesn't he help? New York: Appleton-Century-Crofts, 1970.

(Received for publication September 10, 1973.) 